\title{
AVALIAÇÃO DAS TÉCNICAS DE ANELAMENTO E INSERÇÃO DE SABRE EM ÁRVORES DE Eucalyptus grandis VISANDO MAIOR QUALIDADE DA MADEIRA SERRADA
}

\author{
Raquel Marchesan ${ }^{1}$, Pedro Lício Loiola ${ }^{1}$, Mauro Matheus Tecchio ${ }^{2}$, Claudio Gumane Francisco Juizo ${ }^{3}$, \\ Márcio Pereira da Rocha ${ }^{4}$, Ricardo Jorge Klitzke ${ }^{4}$ \\ ${ }^{1}$ Universidade Federal do Paraná, Programa de Pós-Graduação em Engenharia Florestal, Curitiba, Paraná, Brasil - \\ raqmarchesan@gmail.com; pedrlicio@ hotmail.com \\ ${ }^{2}$ Universidade do Oeste de Santa Catarina, Xanxerê, Santa Catarina, Brasil - mauromatheuss@ hotmail.com \\ ${ }^{3}$ Instituto Superior Politécnico de Manica, Chimoio, Moçambique - c.gumane@ gmail.com \\ ${ }^{4}$ Universidade Federal do Paraná, Departamento de Engenharia e Tecnologia Florestal, Curitiba, Paraná, Brasil - \\ mprocha1@gmail.com; rklitzke@ufpr.br \\ Recebido para publicação: 02/03/2015 - Aceito para publicação: 17/08/2015
}

\begin{abstract}
Resumo
Este trabalho teve como objetivo avaliar duas técnicas de intervenções em um povoamento de Eucalyptus grandis Hill ex Maiden, através dos tratamentos de anelamento prolongado e a inserção do sabre de motosserra até a medula da árvore em dois períodos distintos, 70 e 100 dias. Essas intervenções, por sua vez, tiveram o objetivo de minimizar os defeitos provocados pela liberação das tensões de crescimento da madeira de Eucalyptus grandis durante o desdobro das toras. Para isto, foram derrubadas 25 árvores de um plantio de Eucalyptus grandis com 20 anos de idade, em que, foram utilizadas 5 árvores para cada tratamento avaliado. Como parâmetro de comparação, quantificou-se o número de tábuas que apresentaram rachaduras na extremidade, o índice de rachadura de extremidade (IRT\%) e o rendimento em madeira serrada $(\mathrm{R} \%)$. As técnicas avaliadas apresentaram diferença estatística entre si pelo teste de Tukey, com redução de até $67,40 \%$ de tábuas que apresentaram rachaduras de extremidade. $\mathrm{O}$ rendimento mostrou-se satisfatório para as árvores que tiveram intervenções, proporcionando menos perda de madeira na forma de destopo, principalmente para a técnica de inserção do sabre da motosserra até a medula das árvores com abate após a 100 dias.

Palavras-chave: Rendimento; desdobro; tensão de crescimento.
\end{abstract}

\begin{abstract}
Technical assessment of girdling and incorporation of chainsaw in Eucalyptus grandis trees aiming to greater quality production of lumber. This work aimed to evaluate two intervention techniques in a stand of Eucalyptus grandis Hill ex Maiden, by prolonged girdling treatments and chainsaw sword insertion to the core of tree, in two distinct periods, 70 and 100 days. These interventions aimed to minimize defects caused by the release of growth stress of Eucalyptus grandis during the sawing of logs. In order to that, we cut down 25 trees in a 20 years old plantation of Eucalyptus grandis, we used 5 trees for each assessed treatment. As parameter of comparison, we quantified the number of boards that had cracks in the end, the crack index (IRT\%) of boards and the yield of lumber (R\%). The evaluated techniques revealed statistical differences by Tukey test, with a reduction of up to $67.40 \%$ of boards that had end cracks. The yield was satisfactory for trees that had interventions, providing less loss of wood due to heading, mainly for chainsaw insertion technique to the core of trees, with total cutting after 100 days. Keywords: Yielding; unfolding; growth stress.
\end{abstract}

\section{INTRODUÇÃO}

As tensões de crescimento foram definidas pela Sociedade Americana de Florestas como forças encontradas nos troncos lenhosos verdes, sendo distintas das tensões e deformações que ocorrem durante a secagem da madeira (DINWOODIE, 1966). As primeiras tentativas de explicar as origens das tensões de crescimento foram realizadas em 1928 nos estudos de Martley, onde o autor observou curvaturas que ocorriam em madeiras de olmo após o desdobro em pranchas, enquanto, Jacobs em 1938, sugeriu que a origem das tensões de crescimento é resultado de um possível encurvamento da nova camada de 
crescimento da madeira que ocorre em um determinado estágio de desenvolvimento da célula (BOYD, 1972; BELTRAME et al., 2012).

Tensões de crescimento é uma característica intrínseca do tronco de todas as árvores, que tem como função manter a árvore em pé, em função à ação do peso de sua copa e outros fatores como ventos, galhos e relevo do terreno (SOUZA et al., 2003). As tensões de crescimento possuem o papel de fornecer suporte a árvore ao longo de sua vida, regulando a posição de sua copa em resposta às condições ambientais que são impostas, no entanto, após o abate as árvores ocorrem imediatamente as deformações e rachaduras nos topos das toras, pois ocorrem a modificação do estado de equilíbrio que atuava enquanto a arvore viva. Desta forma sob forças de tração as zonas periféricas da tora tende a expandir e empurrar a face do corte para o exterior causando as rachaduras de topo (TRUGILHO et al., 2006).

As madeiras de folhosas apresentam maiores tensões de crescimento que as madeiras de coníferas, e ainda dentro das folhosas, o gênero Eucalyptus apresentam altas tensões. Como consequência, na madeira dessas espécies apresentam maiores índices de rachaduras e empenamentos no topo das toras e na madeira serrada, ocasionando perdas significativas durante o processamento mecânico da madeira (CONRADIE, 1980; YANG et al., 2005).

As causas dos altos índices de tensões de crescimento ainda não são bem conhecidas, mas há suspeitas de que estejam relacionadas com fatores genéticos, idade da árvore, diâmetro da tora, taxa de crescimento e inclinação do fuste (HUANG et al., 2010).

De acordo com Del Menezzi; Nahuz (1998), muitos fatores externos, ambientais ou silviculturais, podem influenciar a intensidade das tensões de crescimento, como a taxa de crescimento, desrama, desbaste, espaçamento das árvores dentro de um plantio, manejo florestal, tipo de solo e ocorrência ventos.

Fernandes (1989) afirmou que as rachaduras e empenamentos oriundos da madeira em uma umidade acima do ponto de saturação das fibras são consequências das tensões de crescimento. Portanto, as avaliações efetuadas em toras recém abatidas podem não manifestar a intensidade total das tensões de crescimento antes do desdobro, porém podem refletir o nível de intensidade dessas forças no momento do processamento mecânico das toras, até um período de cerca de 72 horas.

Mesmo se sabendo da importância do conhecimento e efeitos das tensões de crescimento para a utilização da madeira, os resultados obtidos no Brasil ainda não foram devidamente esclarecedores. Porém, já foram desenvolvidas técnicas satisfatórias do ponto de vista técnico e econômico para minimizar os efeitos dessas tensões. Em função da crescente utilização das madeiras do gênero Eucalyptus como matéria prima para produtos sólidos, vários questionamentos têm surgido sobre os níveis, efeitos, variações e possíveis formas de controle das tensões de crescimento (FERNANDES, 1989; MATOS et al., 2003; GARCIA; LIMA, 2006).

Montagna et al. (1991), estudando métodos de desdobro em Eucalyptus grandis, visando minimizar o efeito das tensões de crescimentos, constataram que o desdobro realizado pelo sistema de corte a $1 / 3$ do raio da tora apresentou menores índices de rachaduras nas tábuas quando comparadas ao desdobro pelo sistema de cortes paralelos. Del Menezzi; Nahuz (1998) relatou que a execução de cortes balanceados como os realizados por Montagna et al. (1991), provocam a liberação gradual das tensões de crescimento em ambos os lados da tora, obtendo-se assim, melhor precisão do corte das peças. O desdobro de forma alternada reduz as distorções quanto ao desbitolamento em função dos empenamentos ocasionados pelas tensões de crescimento, fato que, ocorrem o balanceamento das forças de tração e compressão das regiões celulares contíguas.

Cardoso Junior et al. (2005), avaliando clones de híbridos de Eucalyptus, constataram que o aumento do espaçamento entre árvores diminuiu a deformação residual longitudinal, mostrando uma ferramenta para o plantio de árvores com produção de madeira com menores tensões de crescimento.

Segundo Severo e Tomaselli (2000) o tratamento térmico é eficiente sobre os níveis de tensões de crescimentos, o qual proporcionou menor deformação radial quando comparada as testemunhas.

Severo e Tomaselli (2000); Calonego e Severo (2005) estudaram o efeito da vaporização na redução das tensões de crescimento em toras e constataram que essa técnica apresenta redução significativa das tensões de crescimento, desde que conduzida de forma adequada em relação à temperatura máxima e tempo de vaporização. Jara et al. (1997) avaliando também o efeito do tratamento térmico na redução das tensões de crescimento em toras de Eucalyptus grandis com 19 anos de idade, constataram que toras aquecidas por 67 horas a $64,5{ }^{\circ} \mathrm{C}$ apresentaram uma redução significativa das tensões de crescimento, aumentando o rendimento em madeira serrada e diminuindo o índice de rachaduras das tábuas. Matos et al. (2003), avaliando cinco técnicas de redução das tensões de 
crescimento na madeira de Eucalyptus dunnii Maiden, com 13 anos, observaram que o anelamento do tronco da árvore resultou em redução das rachaduras das tábuas obtidas durante o processamento primário.

Técnicas alternativas para a minimização das tensões de crescimento também têm surgido, como o uso do herbicida imazapyr, através da sua aplicação nas árvores em pé. Matos et al. (2003) utilizaram esse herbicida em árvores de Eucalyptus dunnii, entretanto, a técnica de anelamento e morte da árvore em pé foram os métodos mais eficientes na redução das tensões de crescimento, pelo fato da morte das árvores ocasionarem a perda de umidade ainda em pé, reduzindo o gradiente de umidade formado logo após o abate, consequentemente minimizando os efeitos das tensões de crescimento.

Segundo Valle (2014) as tensões de crescimento têm origem na camada cambial do tronco e são geradas em função das deposições consecutivas de novas camadas de células a partir do câmbio, durante o desenvolvimento da planta. A tendência dessas novas células é a expansão lateral, enquanto que ao mesmo tempo, se contraem no sentido longitudinal.

A técnica, inserção do sabre da motosserra transversalmente consiste na entrada do sabre da casca até a medula da árvore a $40 \mathrm{~cm}$ acima do solo, atingindo o sistema cambial e obstruindo parte do tecido vascular, diminuindo o fluxo ascendente de seiva bruta no tronco e consequentemente morte lenta da árvore. Essa técnica é pouco conhecida cientificamente, mas que vem sendo usada com frequência por ser de fácil aplicação e também apresentar resultados positivos na liberação das tensões de crescimento. Outra técnica comum é o anelamento de árvore em pé, que segundo Vale (2014), consiste na retirada de tecido lenhoso ao longo de todo o diâmetro do tronco compreendendo uma profundidade de aproximadamente $1 / 3$ do raio da árvore a uma altura de 20 a $30 \mathrm{~cm}$ acima da linha de corte, com o intuito de afetar o seu sistema cambial.

Essas técnicas visam à morte ou a redução da atividade metabólica da árvore, minimizando os efeitos das tensões de crescimento no desdobro das toras pois segundo Valle (2014) com a inserção do sabre da motosserra transversalmente ao tronco da árvore em pé, bem como no anelamento da árvore, ocorre a cessação da atividade cambial, interrompendo assim a adição de novas camadas de células ao tronco que causam o estado de tensão, evitando que tais tensões sejam distribuídas pelo tronco da árvore de forma cumulativa em função das sucessivas composição de camadas de novas células.

Durante o uso dessas técnicas algumas precauções devem ser adotadas, dentre elas, a perda excessiva de umidade de forma capilar, pois um elevado gradiente de umidade pode ocasionar tensões de secagem, provocando rachaduras na seção transversal das toras antes do desdobro. Outro cuidado a ser tomado é o tempo de permanência da árvore no povoamento florestal, em função da possibilidade de ataque de organismos xilófagos. A finalidade da intervenção no povoamento com estas técnicas é minimizar as consequências das liberações das tensões de crescimento da madeira de Eucalyptus grandis no desdobro, assim, minimizando os índices de rachaduras de extremidades.

Em função das grandes perdas que ocorrem na indústria de madeira serrada, proveniente dos defeitos causados pelas tensões de crescimento, tanto no processo de desdobro como no processo de secagem da madeira, este trabalho teve como objetivo avaliar duas técnicas para minimizar as tensões de crescimento em Eucalyptus grandis Hill ex Maiden com vistas a contribuir para a melhoria da qualidade da madeira e aumentar o rendimento em madeira serrada isenta de rachaduras.

\section{MATERIAL E MÉTODOS}

Para a realização do trabalho, foram selecionadas 25 árvores de Eucalyptus grandis Hill ex Maiden provenientes de um plantio florestal seminal localizado no município de Marechal Borman, estado de Santa Catarina, com 20 anos de idade, altura média de $33,40 \mathrm{~m}$ e diâmetro médio de $35,10 \mathrm{~cm}$.

As árvores foram selecionadas em função de seus aspectos fitossanitários, livres de ataque de organismos xilófagos, falta de nutrientes, injúrias mecânicas e diâmetro médios semelhantes, a fim de minimizar a influência do diâmetro das árvores.

Neste estudo foram utilizadas duas técnicas para minimizar as tensões de crescimento, o anelamento prolongado e a inserção do sabre de motosserra até a região da medula das árvores. Tendo o sabre da motosserra dimensões de $50 \mathrm{~cm}$ de comprimento e $7 \mathrm{~cm}$ de largura.

Das 25 árvores avaliadas, 10 delas foram submetidas ao tratamento de anelamento, 10 ao tratamento de inserção de sabre da motosserra e 5 serviram como controle (testemunhas), não recebendo nenhuma intervenção (Tabela 1).

FLORESTA, Curitiba, PR, v. 45, n. 4, p. 695- 704 , out. / dez. 2015.

Marchesan, R. et al.

ISSN eletrônico 1982-4688 / ISSN impresso 0015-3826

697

DOI: $10.5380 /$ rf.v45i4.35776 
Tabela 1. Tratamentos aplicados por cada repetição de toras.

Table 1. Treatments applied by each $\log$ s repetition.

\begin{tabular}{lcc}
\hline Tratamento & Período (dias) & Repetições (toras) \\
\hline 1-Anelamento & 70 & 5 \\
2-Anelamento & 100 & 5 \\
3-Inserção do sabre da motosserra & 70 & 5 \\
4-Inserção do sabre da motosserra & 100 & 5 \\
5-Testemunha & 100 & 5 \\
\hline
\end{tabular}

Após a aplicação dos tratamentos (Figura 1), foi feito um acompanhamento a cada 15 dias no povoamento para a observação do comportamento das árvores, referente a ocorrência ou não de degradação biológica.

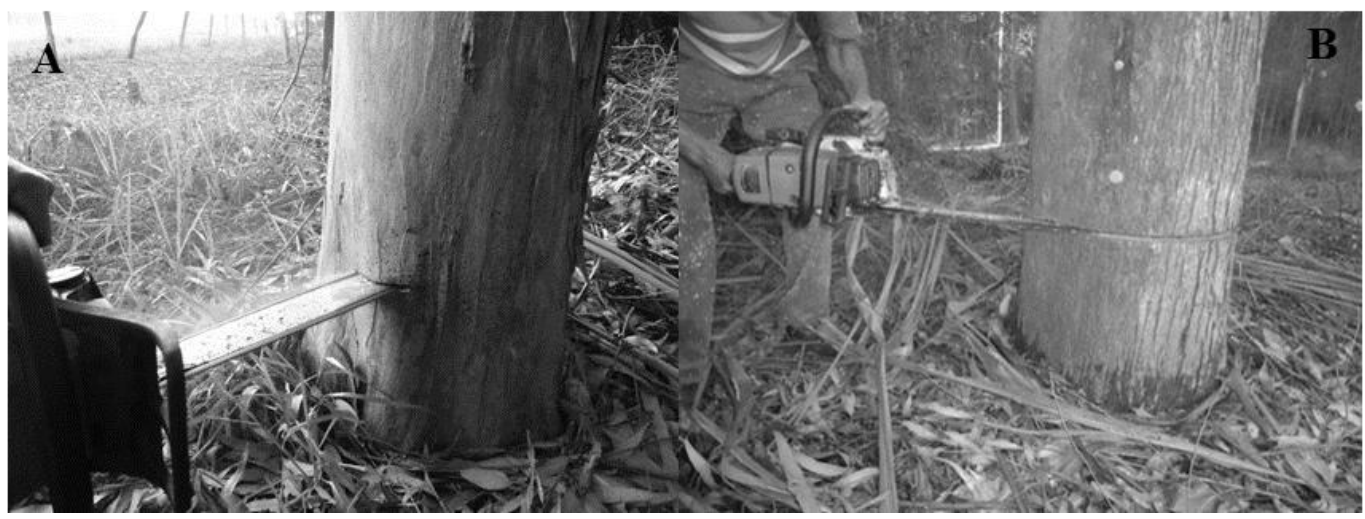

Figura 1. Aplicação do sabre no tronco da arvore (A); Anelamento do tronco da árvore (B).

Figure 1. Chainsaw application in the tree trunk (A); Tree trunk girdling (B).

Depois de um período de 70 dias após a aplicação dos tratamentos, foram derrubadas com o auxílio de uma motosserra, 5 árvores com anelamento e 5 árvores com a inserção do sabre da motosserra. Após a derrubada, os troncos das árvores foram traçados para o comprimento de 6 metros, sendo identificada a primeira tora de cada árvore. Em seguida, as toras foram transportadas até o pátio da serraria, onde foram separadas por tratamento e seccionadas em duas toras de $3 \mathrm{~m}$ de comprimento cada.

Depois de seccionadas, foi determinado o volume das toras por cubagem rigorosa pelo método de Newton. Para a realização dessa cubagem foram feitas três medições de circunferência, uma em $0,10 \mathrm{~m}$, a segunda em $1,50 \mathrm{~m}$ e a última em $2,90 \mathrm{~m}$ de comprimento da tora. Com as medidas da circunferência, estimou o diâmetro de cada seção dividindo a circunferência obtida valor do PI $(\pi)$. Para medição dos comprimentos das toras utilizou-se uma trena.

Após a cubagem, as toras foram desdobradas em uma serra fita vertical, com dimensões de serra de $8,4 \mathrm{~m}$ de comprimento e $1,2 \mathrm{~mm}$ de espessura, volante de $1,10 \mathrm{~m}$ de diâmetro e potência do motor de $60 \mathrm{hp}$. Para todas as toras utilizou-se o sistema de desdobro tangencial com cortes alternados. $\mathrm{O}$ qual consiste em girar a tora em cima do carro porta-toras até a formação de bloco fazendo a alternância dos cortes das tábuas com $25 \mathrm{~mm}$ de espessura. Este sistema de desdobro reduz as distorções quanto ao desbitolamento em função dos empenamentos que ocorrem nas tábuas obtidas e no bloco remanescente. Tal técnica consiste na utilização de uma régua guia, sendo possível controlar a bitola entre a régua e a serra fita. O uso da mesma oferece um controle mais preciso sobre as dimensões das peças que estão sendo processadas (Figura 2). As tábuas com presença de refilos foram encaminhadas para uma refiladeira de mesa, onde foi feito o ajuste das larguras que variaram de 75 a $300 \mathrm{~mm}$ e em seguida foram encaminhadas para uma destopadeira, onde tiveram seu comprimento reduzido para $2,9 \mathrm{~m}$.

Após o desdobro, as tábuas foram identificadas e separadas por tratamento. Em seguida, foram feitas as medições de largura, espessura e comprimento das tábuas para o cálculo do rendimento em madeira serrada verde (Rs\%). Realizou-se também medições da largura e comprimento das rachaduras presentes nas duas extremidades das tábuas para a determinação do rendimento em madeira serrada sem 
rachadura (Rs/r\%). A mesma metodologia foi utilizada para as 10 árvores restantes que permaneceram no campo durante 100 dias e que passaram pelos mesmos tratamentos submetidos às árvores com 70 dias em campo. Em relação às testemunhas, foram utilizadas 5 árvores, porém sem nenhuma intervenção.

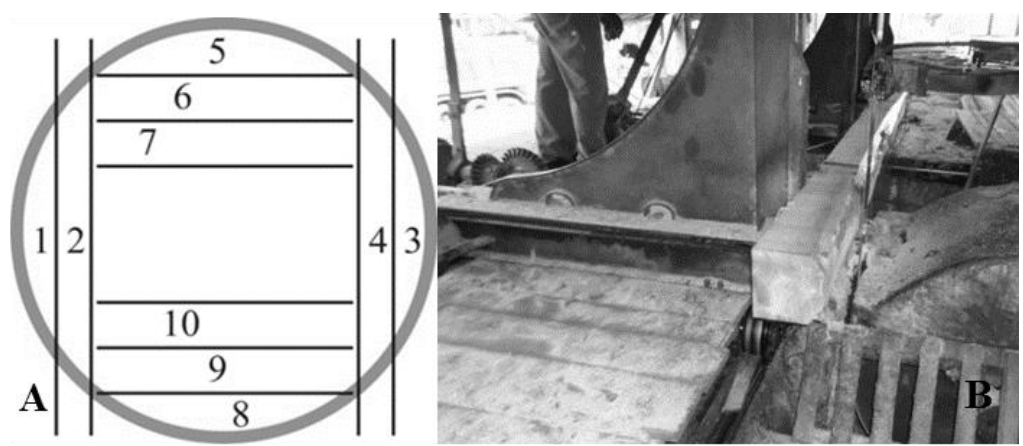

Figura 2. Formação do bloco no modelo de desdobro utilizado (A) desdobro na serra fita horizontal (B). Figure 2. Block formation in the unfolding model used (A), unfolding in the horizontal band saw (B).

Para avaliar o grau de significância das porcentagens de tábuas com rachaduras nas extremidades após o desdobro, para as diferentes técnicas analisadas (anelamento e inserção do sabre com desdobro ocorrendo em 70 e 100 dias), bem como a variação existente entre as técnicas empregadas para a porcentagem de rachaduras de extremidades nas tábuas, realizou-se uma análise de variância com delineamento inteiramente casualizado. Foram utilizadas 5 repetições por tratamento, totalizando 25 árvores derrubadas, e quando significativa, aplicou-se o teste Tukey a 5\% de probabilidade de erro para a comparação de médias.

Foram realizadas análises referentes a rendimentos em madeira serrada, rendimento em madeira serrada sem rachadura, índice de rachaduras de extremidades nas tábuas, bem como, a porcentagem de tábuas que apresentaram rachaduras de extremidades. Os resultados estatísticos foram obtidos através da

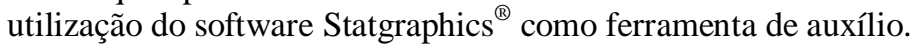

\section{RESULTADOS E DISCUSSÃO}

Foi verificado pela análise de variância ao nível de significância de $1 \%$ de probabilidade de erro para a porcentagem de tábuas serradas que apresentaram rachaduras de extremidades para os tratamentos avaliados - anelamento e inserção de sabre com dois tempos distintos de desdobro (70 e 100 dias) e para as tábuas controle (testemunha). Essas técnicas causam redução da circulação de seiva na árvore e com isso as tensões de crescimento são amenizadas.

Os tratamentos empregados (Tabela 2) proporcionaram minimização dos efeitos ocasionados pelas tensões de crescimento nas madeiras de Eucalyptus grandis durante o desdobro das toras proporcionado melhorias. As toras que não tiveram nenhuma intervenção (anelamento ou inserção do sabre da motosserra) apresentaram maior quantidade de tábuas com defeitos, como rachaduras de extremidades $(45,46 \%)$, diferindo-se dos tratamentos empregados, com exceção da técnica de anelamento com o desdobro após 70 dias. Marchesan et al. (2011), em estudo semelhante, também constatou que as técnicas empregadas para minimizar os efeitos das tensões de crescimento proporcionaram a produção de tábuas com menos índices de rachaduras, sendo a inserção do sabre da motosserra com valores de 22,09\% e a técnica de anelamento com valores de $35,28 \%$ de tábuas com rachaduras. Os autores também enfatizaram que essa última técnica também apresentou rachaduras longitudinais menores nas extremidades.

Para as outras técnicas empregadas, observa-se que a inserção do sabre da motosserra associado ao desdobro após 100 dias da intervenção se mostrou como a técnica mais eficiente na minimização dos efeitos da tensão de crescimento. Nesse tratamento apenas $14,82 \%$ das tábuas produzidas apresentaram rachaduras de extremidades, entretanto esse tratamento não diferiu estatisticamente das técnicas de anelamento com o desdobro após 100 dias $(22,73 \%$ de tábuas com rachaduras nas extremidades) e da inserção do sabre da motosserra com desdobro após 70 dias $(25,49 \%)$. 
Tabela 2. Porcentagem de tábuas com rachaduras nas extremidades para cada tratamento avaliado após o desdobro.

Table 2. Percentage of boards with cracks at the ends for each treatment evaluated after the unfolding process.

\begin{tabular}{lccc}
\hline Tratamento & Dias & $\begin{array}{c}\text { Porcentagem de tábuas com } \\
\text { rachaduras nas extremidades }\end{array}$ & F \\
\hline Anelamento & 70 & $44,44 \mathrm{bc}$ & \\
Anelamento & 100 & $22,73 \mathrm{ab}$ & $8,66^{* *}$ \\
Inserção do sabre da motosserra & 70 & $25,49 \mathrm{ab}$ & \\
Inserção do sabre da motosserra & 100 & $14,82 \mathrm{a}$ & \\
Testemunha & - & $45,46 \mathrm{c}$ & \\
\hline
\end{tabular}

"Significativo ao nível de 1\% de probabilidade. As médias seguidas por uma mesma letra minúscula, na vertical, não diferem entre si (Tukey $\mathrm{p} \geq 0,05)$.

Souza et al. (2003) estudando deformação residual longitudinal e sua relação com algumas características de crescimento e da madeira em clones de Eucalyptus, observaram a ocorrência de rachaduras longitudinais nas extremidades em quase todas as tabuas produzidas, valores estes superiores ao encontrados neste trabalho. Trugilho et al. (2006), avaliando as tensões de crescimento em clones de Eucalyptus, observou a ocorrência de rachaduras em quase todas as tábuas produzidas.

$\mathrm{Na}$ técnica de anelamento das árvores, não houve diferença estatística ao nível de 5\% de significância para os dois períodos de desdobro (70 e 100 dias), sendo os valores percentuais de rachaduras nas extremidades das tábuas foram de 16,04 e 13,20\%, respectivamente. Apesar de não haver diferença dentro da técnica de anelamento, evidenciou um menor índice de rachaduras quando aplicado o anelamento das árvores e o desdobro após 100 dias.

Observa-se (Tabela 3) que para a técnica de inserção de sabre os valores percentuais de rachaduras nas extremidades foram de $12,62 \%$ e $10,58 \%$ para 70 e 100 dias, respectivamente, não diferindo pelo teste de Tukey ao nível de $5 \%$ de significância. A mesma tendência observada para a técnica de anelamento pode ser observado para a técnica da inserção do sabre da motosserra até a medula das árvores, sendo que para o maior tempo de desdobro (100 dias), as consequências das tensões de crescimento foram minimizadas, obtendo valores próximos a $10 \%$ de rachaduras nas extremidades nas tábuas produzidas.

Na tabela 3 consta os valores médios obtidos de volume de madeira serrada com rachaduras nas extremidades, rendimento em madeira serrada com rachaduras nas extremidades, percentuais de tábuas com rachaduras nas extremidades e porcentagem de rachaduras nas tábuas.

Tabela 3. Valores médios de volume de madeira serrada com rachaduras nas extremidades, rendimento em madeira serrada com rachaduras nas extremidades, percentuais de tábuas com rachaduras nas extremidades e índice de rachaduras nas tábuas.

Table 3. Mean values of lumber volume with cracks at the ends, yield of lumber with cracks at the ends, percentage of boards with cracks at the ends and index of the board's cracks.

\begin{tabular}{lccccccc}
\hline $\begin{array}{l}\text { Tempo } \\
(\mathbf{d i a s})\end{array}$ & Tratamento & $\begin{array}{c}\mathbf{T} \\
\mathbf{t b} \mathbf{~ c / r}\end{array}$ & $\begin{array}{c}\mathbf{T} \\
\mathbf{t b} \mathbf{~ s} / \mathbf{r}\end{array}$ & $\begin{array}{c}\mathbf{V ~ c / r} \\
\left(\mathbf{m}^{\mathbf{3}}\right)\end{array}$ & $\begin{array}{c}\mathbf{V ~ s} / \mathbf{r} \\
\left(\mathbf{m}^{3}\right)\end{array}$ & $\begin{array}{c}\% \\
\text { tb r }\end{array}$ & $\begin{array}{c}\mathbf{\%} \\
\text { IRT }\end{array}$ \\
\hline 70 & Anelamento & 24 & 30 & 0,371 & 0,379 & 44,44 & 16,04 \\
& Sabre & 13 & 38 & 0,206 & 0,520 & 25,49 & 12,62 \\
\hline 100 & Anelamento & 10 & 34 & 0,151 & 0,404 & 22,73 & 13,20 \\
& Sabre & 8 & 46 & 0,119 & 0,553 & 14,82 & 10,58 \\
\hline--- & Testemunha & 25 & 30 & 0,396 & 0,368 & 45,46 & 22,36 \\
\hline
\end{tabular}

$\mathrm{T}$ tb: total de tábuas produzidas; $\mathrm{T}$ tb c/r: total de tábuas com rachaduras; $\mathrm{T}$ tb $\mathrm{s} / \mathrm{r}$ : total de tábuas sem rachaduras; $\mathrm{V}$ c/r $\left(\mathrm{m}^{3}\right)$ : volume em madeira serrada com rachaduras; $\mathrm{V} \mathrm{s} / \mathrm{r}\left(\mathrm{m}^{3}\right)$ : volume em madeira serrada sem rachadura; \% tb $\mathrm{r}$ : porcentagem de tábuas com rachaduras; \% IRT: Porcentagem de índice de rachaduras nas tábuas.

Na tabela 4 consta valores médios de rendimento em madeira serrada total e rendimento em madeira serrada sem rachaduras nas extremidades.

Os rendimentos totais obtidos neste trabalho estão em conformidade com outros trabalhos que utilizaram madeiras de plantios florestais com idades próximas a 20 anos. Entretanto, nesse trabalho foram obtidos valores superiores de rendimento em madeira serrada em função do sistema de desdobro 
utilizado. Pode-se observar na tabela 4 que o processo de destopo das tábuas para retirada das rachaduras ocasionou uma queda abrupta nos rendimentos totais, principalmente, para o desdobro das árvores que não tiveram nenhuma intervenção no povoamento florestal.

Tabela 4. Valores médios de rendimento total em madeira serrada e rendimento em madeira serrada sem rachaduras nas extremidades.

Table 4. Mean values of total yield in lumber and yield in lumber without cracks at the ends.

\begin{tabular}{lccccc}
\hline $\begin{array}{l}\text { Tempo } \\
(\mathbf{d i a s})\end{array}$ & Tratamento & $\begin{array}{c}\mathbf{V t} \\
\left(\mathbf{m}^{\mathbf{3}}\right)\end{array}$ & $\begin{array}{c}\text { Vs } \\
\left(\mathbf{m}^{\mathbf{3}}\right)\end{array}$ & $\begin{array}{c}\mathbf{R s} \\
(\mathbf{\%})\end{array}$ & $\begin{array}{c}\mathbf{R s} / \mathbf{r} \\
(\mathbf{\%})\end{array}$ \\
\hline \multirow{2}{*}{70} & Anelamento & 1,347 & 0,749 & 55,62 & 34,96 \\
& Sabre & 1,182 & 0,725 & 61,35 & 43,96 \\
\hline \multirow{2}{*}{100} & Anelamento & 1,083 & 0,555 & 51,23 & 37,31 \\
& Sabre & 1,254 & 0,672 & 53,60 & 44,09 \\
\hline-- & Testemunha & 1,337 & 0,764 & 57,11 & 28,86 \\
\hline
\end{tabular}

Vt $\left(\mathrm{m}^{3}\right)$ : Volume de toras; Vs $\left(\mathrm{m}^{3}\right)$ : Volume em madeira serrada; Rs (\%): Rendimento em madeira serrada total; Rs/r(\%) Rendimento em madeira serrada sem rachadura.

Para o desdobro das toras em que foi realizado o anelamento das árvores, houve uma redução do rendimento total de $55,62 \%$ (70 dias) e $51,23 \%$ (100 dias) para $34,96 \%$ e 37,31\%, respectivamente. Já as toras em que se utilizou a técnica de inserção de sabre da motosserra até a medula, o rendimento total caiu de $61,35 \%$ (70 dias) e 53,60\% (100 dias) para 43,96\% e 44,09\%, respectivamente. Para a testemunha, o rendimento total caiu de $57,11 \%$ para $28,86 \%$. Nota-se que a técnica da inserção de sabre no motosserra por 100 dias foi o tratamento que apresentou a menor perda em madeira serrada $(17,74 \%)$ em função do destopo para a retirada de rachaduras de extremidades. Entretanto, a testemunha apresentou $49,47 \%$ de perda em madeira serrada em função do destopo, o que torna satisfatório a utilização das técnicas utilizadas nesse trabalho para a minimização das tensões de crescimento, principalmente a técnica de inserção de sabre da motosserra com desdobro em 100 dias. Tal técnica além de apresentar facilidade de aplicação em relação ao anelamento das árvores, possui esforços de trabalho mais ergonômico para o operador, demandando menos tempo para a execução da tarefa, consequentemente menos mão de obra dispendida, reduzindo os custos industriais.

Outro fator importante na utilização dessas técnicas é a redução de até $47,32 \%$ das rachaduras de extremidades nas tábuas, acarretando em aumento do rendimento de madeira serrada sem rachaduras, valorizando a matéria-prima (tora) e reduzindo custos de produção.

O cálculo do rendimento em madeira serrada para o Eucalyptus spp. é influenciado por diversos fatores, como idade, diâmetro, conicidade, dimensões finais dos produtos, maquinário disponível, mão de obra, modelo de corte etc. (GOMIDE, 1977; FERREIRA et al., 2004; VITAL, 2008).

Ferreira et al. (2004) avaliaram o rendimento em madeira serrada para dez clones de Eucalyptus em três modelos de corte e obtiveram valores entre $30,1 \%$ para cortes de costaneiras a $1 / 3$ do raio da tora, $35,20 \%$ para o desdobro paralelo ao centro da tora e 37,20\% para o desdobro paralelo à casca. Nesse trabalho, os autores desconsideraram os produtos obtidos da resserragem dos pranchões centrais e das costaneiras. Scanavaca Junior e Garcia (2003) observaram rendimentos de 42,50\% para a produção de madeira serrada de Eucalyptus urophylla, com 19 anos. Batista e Carvalho (2007), estudando o rendimento em madeira serrada para o gênero Eucalyptus obtiveram valores de $44,80 \%$, valores esses próximos aos obtidos por Monteiro et al., (2013), no qual foram observados rendimentos de até 43,84\%. Já Amparado et al. (2008), avaliando o rendimento e rendimento em madeira serrada de Eucalyptus saligna, com 20 anos, para a confecção de "clear boards" (peças livres de defeitos) encontraram valores próximo a $26 \%$.

\section{CONCLUSÕES}

- As intervenções realizadas nas árvores de Eucalyptus grandis, com as técnicas de anelamanto prolongado e inserção do sabre da motosserra até a medula minimizaram os efeitos das tensões de crescimento no tronco. Isso proporcionou a produção de madeira serrada com menor índice de rachaduras nas extremidades das tábuas, durante o processamento mecânico das toras, obtendo-se maior rendimento em madeira serrada. 
- A técnica de inserção do sabre da motosserra até a medula, com o desdobro ocorrendo após 100 dias da intervenção, foi a que resultou em tábuas com menor proporção de rachaduras de extremidades. As árvores que não tiveram nenhuma intervenção no campo (testemunha) tiveram o menor rendimento e maior quantidade de tábuas com rachaduras nas extremidades.

- Com relação ao índice de rachadura (IRT), a técnica de inserção de sabre da motosserra com desdobro ocorrendo após 100 dias da intervenção, foi a técnica que apresentou o melhor resultado.

- A técnica de inserção do sabre da motosserra até a medula da árvore, além de proporcionar resultados satisfatórios oferece também facilidade e simplicidade na sua aplicação em povoamentos que visam a utilização da madeira serrada.

\section{AGRADECIMENTOS}

Os autores agradecem a empresa Albino Tecchio \& Cia LTDA., pelos auxílios prestados para a realização deste trabalho, com a disponibilização das árvores e pela realização do desdobro das mesmas.

\section{REFERÊNCIAS}

AMPARADO, K. F.; CARVALHO, A. M.; GARCIA, R. A.; LATORRACA, J. V. F. Caracterização do rendimento em madeira serrada de Eucalyptus saligna Smith nas condições verde e seca. Revista Forestal Venezolana, Caracas, v. 52, n. 1, p. 71 - 76, 2008.

BATISTA, D. C.; CARVALHO, A. M. Avaliação do desempenho operacional de uma serraria através de estudo do tempo, rendimento e eficiência. Scientia Forestalis, Piracicaba, n. 75, p. 31 - 38, 2007.

BELTRAME, R.; LAZAROTTO, M.; HASELEIN, C. R.; SANTINI, E. J.; SCHNEIDER, P. R.; AGUIAR, A. M. Determinação das deformações residuais longitudinais decorrentes das tensões de crescimento em Eucalyptus spp. Ciência Florestal, v. 22, n. 2, p. 343 - 351, 2012.

BOYD, J. D. The growth stresses: V. Evidence of an origin in differentiation and lignification. Wood Science and Technology, Berlin, v. 6, p. 251 - 262, 1972.

CALONEGO, F. W.; SEVERO, E. T. D. Efeito do diâmetro de toras na magnitude das tensões de crescimento de Eucalyptus grandis. Energia na agricultura, Botucatu, v. 20, n. 2, p. 53 - 65, 2005.

CARDOSO JUNIOR, A. A.; TRUGILHO, P. F.; LIMA, J. T.; ROSADO, S. C. S.; MENDES, L. M. Deformação residual longitudinal em diferentes espaçamentos e idade em clones de híbridos de Eucalyptus. Cerne, Lavras, v. 11, n. 3, p. 218 - 224, 2005.

CONRADIE, W. E. Utilization of south African grown E. grandis (W. Hill ex Maiden) as veneer log: Part 1. Control of end-splitting in veneer logs. Pretoria: National Timber Research Intitute, 1980. 26 p.

DEL MENEZZI, C. H. S.; NAHUZ, M. A. R. Técnicas de desdobro utilizadas para madeira de eucalipto - uma revisão bibliográfica. Árvore, v. 22, n. 3. Viçosa, p. 415 - 428, 1998.

DINWOODIE, J. M. Growth stresses in timber: a review of literature. Forestry, Oxford, v. 39, n. 2, p. 162 - 170, 1966.

FERNANDES, P. S. Tensões de crescimento em procedência de Eucalyptusgrandis Hill Maiden e suas relações com as características das fibras e densidades básicas. Revista Instituto Florestal, São Paulo. v. 1, n. 1, p. 215 - 234, 1989.

FERREIRA, S.; LIMA, J. T.; ROSADO, S. C. S.; TRUGILHO, P. F. Influência de métodos de desdobro tangenciais no rendimento e na qualidade da madeira de clones de Eucalyptus spp. Cerne, Lavras, v. 10, n. 1, p. 10 - 21, 2004.

GARCIA, J. N.; LIMA, I. L. Efeito do desbaste e da fertilização nas tensões de crescimento em Eucalyptus grandis. Scientia Forestalis, Piracicaba, v. 70, p. 171 - 183, 2006.

GOMIDE, J. L. Serraria. Viçosa, MG: UFV, 1977. 119 p.

HUANG, Y. S.; HUNG, L. F.; KUO-HUANG, L. L. Biomechanical modeling of gravitropic response of branches: roles of asymmetric periphery growth strain versus self-weight bending effect. Trees, v. 24, p. $1151-1161,2010$. 
JARA, E. R. P.; MIRANDA, M. J. DE A. C.; HUMPHREYS, R. D. Influência do tratamento térmico na redução das tensões internas de crescimento em toras de Eucalyptus grandis. In: IUFRO CONFERENCE OR SILVICULTURE AND IMPROVEMENT OF Eucalyptus, 1997, Proceedings... Colombo, 1997.

MARCHESAN, R.; SILVA, J. B.; MATTOS, P. P.; ROCHA, M. P.; SANTOS, P. E. T. Matéria-prima sustentável: estudo da qualidade e rendimento em madeira serrada de Eucalyptus dunni. In: Simpósio Nacional de Tecnologia e Sociedade, 4., 2011, Curitiba. Anais...Curitiba: Universidade Tecnológica Federal do Paraná, 2011. p. 1 - 10.

MATOS, J. L. M.; IWAKIRI, S.; ROCHA, M. P.; PAIM, R. M.; ANDRADE, L. O. Redução do efeito das tensões de crescimento em toras de Eucalyptus dunnii. Scientia Forestalis, Piracicaba, v. 64, p. 128 135, 2003.

MONTAGNA, R. G.; PONCE, R. H.; FERNANDES, P. S.; RIBAS, C. Desdobro de Eucalyptus grandis Hill ex-Maiden visando diminuir o efeito das tensões de crescimento. Revista Instituto Florestal, São Paulo, v. 3, n. 2, p. 181 - 190, 1991.

MONTEIRO, T. C.; LIMA, J. T.; SILVA, J. R. M.; TRUGILHO, P. F.; ANDRADE, B. C. L. Avaliação do desdobro de toras de Eucalyptus para obtenção de peças estruturais. Cerne, Lavras, v. 19, n. 3, p. 357 364, 2013.

SCANAVACA JUNIOR, L.; GARCIA, J. N. Rendimento em madeira serrada de Eucalyptus urophylla. Scientia Forestalis, Piracicaba, n. 63, p. 32 - 43, 2003.

SEVERO, E. T. D.; TOMASELLI, I. Efeito da vaporização no alívio das tensões de crescimento em toras de Eucalyptus dunnii. Scientia Agrária, Curitiba, v. 1, n. 1/2, p. 29 - 32, 2000.

SOUZA, M. A. M.; TRUGILHO, P. F.; LIMA, J. T.; ROSADO, S. C. S. Deformação Residual Longitudinal (DRL) e sua relação com as características de crescimento da árvore em clones de Eucalyptus, Floresta, Curitiba, v. 33, p. 275 - 137, 2003.

TRUGILhO, P. F.; LIMA. J. T.; PÁDUA, F. A.; SORAGI, L. C.; ANDRADE, C. R. Deformação residual longitudinal (DRL) e tangencial (DRT) em seis clones de Eucalyptus spp. Cerne, v. 12, n. 3, p. 279 - 286, 2006.

VALLE, M. L. A. Estratégia de seleção de clones de Toona ciliata M. Roemer Var. australis para biomecânica de árvores e qualidade da madeira. 2014. 74 f. Tese (Doutorado em Engenharia Florestal) - Universidade Federal de Lavras, Lavras, 2014.

VITAL, B. R. Planejamento e operação de serrarias. Viçosa, MG: UFV, 2008. 211 p.

YANG, J. L.; BAILLÈRESB, H.; OKUYAMAC, T.; MUNERID, A.; DOWNESE, G. Measurements methods for longitudinal surface strain in trees: a review. Australian Forestry, v. 68, n. 1 p. 34 - 43, 2005. 
FLORESTA, Curitiba, PR, v. 45, n. 4, p. 695- 704, out. / dez. 2015. Marchesan, R. et al. 